Review Article

\title{
Application of Novel Drugs for Corneal Cell Regeneration
}

\author{
Sang Beom Han $\mathbb{D}^{1},{ }^{1}$ Yu-Chi Liu, ${ }^{2,3,4}$ Karim Mohamed-Noriega $\left(\mathbb{D},{ }^{5}\right.$ \\ and Jodhbir S. Mehta $\oplus^{2,3,4}$ \\ ${ }^{1}$ Department of Ophthalmology, Kangwon National University Hospital, Kangwon National University, \\ Chuncheon, Republic of Korea \\ ${ }^{2}$ Singapore National Eye Centre, Singapore \\ ${ }^{3}$ Singapore Eye Research Institute, Singapore \\ ${ }^{4}$ Department of Ophthalmology, Yong Loo Lin School of Medicine, National University of Singapore, Singapore \\ ${ }^{5}$ Department of Ophthalmology, Faculty of Medicine, University Hospital "Jose E. Gonzalez", Autonomous University of Nuevo Leon, \\ Monterrey, NL, Mexico
}

Correspondence should be addressed to Jodhbir S. Mehta; jodmehta@gmail.com

Received 27 December 2017; Revised 26 February 2018; Accepted 27 March 2018; Published 2 May 2018

Academic Editor: Enrique Mencía-Gutiérrez

Copyright ( 2018 Sang Beom Han et al. This is an open access article distributed under the Creative Commons Attribution License, which permits unrestricted use, distribution, and reproduction in any medium, provided the original work is properly cited.

Corneal transplantation has been the only treatment method for corneal blindness, which is the major cause of reversible blindness. However, despite the advancement of surgical techniques for corneal transplantation, demand for the surgery can never be met due to a global shortage of donor cornea. The development of bioengineering and pharmaceutical technology provided us with novel drugs and biomaterials that can be used for innovative treatment methods for corneal diseases. In this review, the authors will discuss the efficacy and safety of pharmacologic therapies, such as Rho-kinase (ROCK) inhibitors, blood-derived products, growth factors, and regenerating agent on corneal cell regeneration. The promising results of these agents suggest that these can be viable options for corneal reconstruction and visual rehabilitation.

\section{Introduction}

Corneal blindness is one of the leading causes of reversible blindness worldwide [1]. Corneal transplantation has been the only method for the treatment of corneal blindness, of which penetrating keratoplasty has long been the major surgical procedure. More recently, partial thickness corneal transplantation, such as Descemet's stripping endothelial keratoplasty (DSEK), Descemet's membrane endothelial keratoplasty (DMEK), and deep anterior lamellar keratoplasty (DALK), has been gaining popularity due to better visual prognosis and reduced risk of rejection. However, a global shortage of donor corneal tissue makes it impossible to meet the demands for corneal transplantation with current cornea donation programs. In addition, despite the advancement of surgical techniques and devices, corneal transplantation is still associated with limitations, such as graft failure or rejection, difficulty of the surgical procedure, and complications including secondary glaucoma $[2,3]$.
Remarkable developments of novel biomaterials and stem cell-based tissue cultivation and expansion techniques during the past few decades might enable the mass production of synthetic corneal tissue and are expected to provide innovative treatment methods for corneal disease. Medical treatment using drugs, such as Rho-kinase (ROCK) inhibitors, blood-derived products, growth factors, and regenerating agent eye drops (RGTA), is also anticipated to have therapeutic potential. In this review, we aimed to provide information on the pharmacologic therapies for corneal cell regeneration using these drugs.

\section{Rock Inhibitors}

ROCK is a serine/threonine protein kinase that is activated by Rho and forms Rho/ROCK complex that regulates a variety of cellular functions, such as cell proliferation, differentiation, migration, contraction, and apoptosis $[4,5]$. Therefore, the ROCK signaling pathway has drawn interest as a potential 
target for the treatment of diseases of multiple organs $[4,5]$. Recent studies showed that the ROCK inhibitor might be an innovative therapeutic agent for various ocular diseases, particular for corneal endothelial decompensation [4]. Although corneal transplantation has been the only therapy for corneal endothelial dysfunction, studies indicate the potential of ROCK inhibitors as a less-invasive alternative to graft surgery [3].

\subsection{ROCK Inhibitor for Corneal Endothelial Cell (CEC)} Generation. Okumura et al. [6] demonstrated that a selective ROCK inhibitor, Y-27632, promoted CEC proliferation and adhesion and suppressed its apoptosis, indicating that the topical ROCK inhibitor has been therapeutic for CEC regeneration [6]. An experimental study showed that a ROCK inhibitor facilitated the proliferation of CECs by the modulation of cyclin and p27; both are regulators of the G1/S transition [7]. Peh et al. [8] also revealed that Y-27632 increased cell proliferation. In their study, the effect of the ROCK inhibitor on the proliferation of CEC was significant only in the corneas from younger donors, suggesting that CECs from older corneas might lose the proliferation potential that could be activated by the ROCK inhibitor [8]. The findings of another study that Y-27632 had no effect on the proliferation of human CECs, although it facilitated corneal endothelial wound healing ex vivo and in vitro, support the assumption [9].

ROCK inhibitor eye drops enhanced corneal endothelial wound healing in a rabbit CEC injury model $[6,7,10]$. Topical ROCK inhibitor instillation also led to the facilitation of corneal endothelial wound healing and the recovery of corneal transparency in a primate CEC damage model [11]. Y-27632 was also shown to enhance the proliferation and adhesion and suppress the apoptosis of primate CECs cultured in vitro $[6,12]$. Considering that primate CECs also have limited proliferative capacity, these results suggest that the ROCK inhibitor may have a therapeutic effect on human corneal endothelial dysfunction.

Okumura et al. [13] postulated that topical application of the ROCK inhibitor could facilitate the proliferation and migration of the residual CECs after acute corneal endothelial damage, thereby decreasing the risk of corneal endothelial decompensation [13]. A preliminary study showed that topical administration of the ROCK inhibitor resulted in the recovery of corneal transparency in 1-2 months in all 3 patients with postoperative acute corneal endothelial decompensation [3].

The ROCK inhibitor could be an alternative to corneal transplantation for Fuchs' endothelial corneal dystrophy (FECD). A human pilot study demonstrated that treatment with Y-27632 eye drops for patients with FECD resulted in the decrease in central corneal thickness and the recovery of corneal transparency in patients with corneal edema confined to the center, whereas the effect was not evident in those with diffuse corneal edema $[3,11,14]$. A recent case series study also revealed that descemetorhexis without graft surgery followed by topical ROCK inhibitor administration resulted in the restoration of corneal clarity and visual rehabilitation in patients with FECD [15].
2.2. ROCK Inhibitor for Tissue Engineering. For the treatment of corneal endothelial decompensation, the following two strategies for tissue engineering appears to be promising [1]: transplantation of bioengineered corneal endothelial cell sheet and [2] direct injection of cultivated CEC suspension to the anterior chamber [3].

Experimental studies showed that the transplantation of cultivated CECs on a collagen sheet can result in the restoration of corneal transparency and reduction of corneal edema $[16,17]$. However, manipulation of the fragile monolayer sheet in the anterior chamber is technically challenging and is associated with the risk of CEC loss [3].

Theoretically, direct injection of CECs into the anterior chamber might be simple and less invasive compared to CEC sheet transplantation. In addition, the preparation of cells for transplantation may be easier, without the need for an artificial substrate [3]. The risk of CEC damage during the procedure might also be reduced. As the CECs injected into the anterior chamber may not spontaneously attach to Descemet's membrane, methods for improving the adhesion of the injected CECs have been attempted, such as magnetic guidance of iron powder or superparamagnetic microspheres incorporated in the CECs [18-20].

Considering that the ROCK inhibitor was proven to promote CEC adhesion onto a substrate [12], it may be postulated that the ROCK inhibitor can be helpful for promoting the attachment of CECs injected into the anterior chamber. An experimental study using a rabbit corneal endothelial dysfunction model demonstrated that intracameral injection of rabbit CECs combined with Y-27632, followed by keeping each rabbit in the facedown position for $3 \mathrm{hr}$, achieved enhanced attachment of donor cells onto host Descemet's membrane and the restoration of corneal transparency [21], whereas CEC injection without the inclusion of Y-27632 led to persistent corneal edema [21].

Y-27632 also promoted the adhesion of intracamerally injected CECs onto Descemet's membrane in both rabbit and primate corneal endothelial decompensation models and upregulated the expression of functional proteins including $\mathrm{Na}+/ \mathrm{K}+\mathrm{ATPase}$ and $\mathrm{ZO}-1$, thereby leading to the resolution of corneal edema [22]. Another study revealed that intracameral injection of either human or monkey CECs in combination with Y-27632 led to the regeneration of monkey corneal endothelium, suggesting that intracameral injection of cultivated human CECs combined with the ROCK inhibitor may be a plausible therapeutic option for corneal endothelial diseases [2]. Preliminary data from a human clinical study showed that cultured human CECs injected in conjunction with ROCK achieved improvement of corneal edema and visual acuity without any serious adverse effect [3]. Although the results appear to be promising, further prospective randomized studies with a long-term follow-up are necessary to evaluate the efficacy and safety of ROCK inhibitors for the treatment of corneal endothelial diseases [3].

2.3. Other Effects of ROCK Inhibitor on Corneal Regeneration. The ROCK inhibitor was suggested to have additional effects that can be potentially applicable for corneal regeneration. $\mathrm{Y}-27632$ was shown to promote both ex vivo and in vitro 
proliferation of limbal epithelial cell proliferation, suggesting it can be useful for the treatment of limbal stem cell deficiency [23]. Zhou et al. [24] also demonstrated that Y27632 enhanced the cloning efficiency of limbal stem/progenitor cells by promoting their adhesion and capacity of reactive oxygen species scavenging in a rabbit model [24]. Y-27632 inhibited the transition of rabbit keratocyte to myofibroblast and modulated a wound healing process after a superficial lamellar keratectomy in a rabbit cornea [25]. Animal experimental studies revealed that ROCK inhibitors, fasudil and AMA0526, inhibited corneal neovascularization and opacity and facilitated corneal epithelial regeneration after corneal alkali burn $[26,27]$.

\section{Blood-Derived Products}

Application of blood-derived products for ocular surface diseases was first introduced in 1975 for 6 patients with chemical burns [28]. Since Tsubota et al. [29, 30] proved the efficacy and safety of autologous serum eye drops (ASE) for the treatment of dry eye disease (DED) and persistent epithelial defect (PED) $[29,30]$, studies have proven that blood-derived products are innovative therapeutic agents for various ocular surface disorders, such as DED [31], PED [32], neurotrophic keratitis [33], recurrent corneal erosion [34], and chemical burns [35].

3.1. Autologous Serum Eye Drops (ASE) [36]. ASE has a similar biochemical composition as human tears [37] and includes growth factors including epidermal growth factor (EGF) and transforming growth factor- (TGF-) $\beta$ [38], chemokines, fibronectin, and various nutrients [38].

Consensus for the preparation method has never been established yet [37]. An in vitro experimental study indicated that an increased clotting time of 120 min or longer, a sharp centrifugation $(3000 \mathrm{~g}$ for $15 \mathrm{~min}$ ), and dilution with balanced salt solution at $12.5-25 \%$ were optimal for corneal epithelial healing [39]. Clinically, 20\% ASE is most frequently used to match the TGF- $\beta$ concentration, which is 5 times higher in serum than in tears, to prevent delayed wound healing and promotion of corneal haze caused by TGF- $\beta$ [30]. However, higher concentrations of ASE (50 to 100\%) were also suggested to be effective and safe [40, 41]. A randomized prospective study showed that $100 \%$ ASE was more effective for the treatment of PED, Sjögren's syndrome (SS), and nonSjögren DED than 50\% ASE [42].

Randomized clinical studies revealed that ASE was more effective than conventional treatment for the improvement of both symptoms and signs of DED [43-45]. Kojima et al. [46] demonstrated that ASE suppressed apoptosis in the ocular surface epithelium and albumin contained in ASE recovered ocular surface damage [46]. ASE was superior to artificial tear in the improvement of dry eye signs after refractive surgery [47]. In addition, ASE can be a therapeutic option for PED refractory to conventional treatment [40, 48]. Schrader et al. [49] suggested that ASE combined with silicone hydrogel contact lenses might be helpful in recalcitrant PED [49]. Moreover, ASE was shown to be effective in facilitating reepithelialization of corneal graft after penetrating keratoplasty
[50]. It also promoted corneal epithelial healing in patients with neurotrophic keratitis and aniridic keratopathy [51, 52]. A prospective study with a long-term follow-up revealed that ASE was effective for the prevention of recurrence in patients with recurrent corneal erosion [53]. However, a review of five randomized clinical trials that compared AS versus artificial tears or saline in DED patients revealed that no evidence of a benefit was found after two weeks of treatment, although there might be some short-term effect on symptoms with AS compared with artificial tears [54]. Therefore, we also believe further well-designed, large-scale randomized controlled studies are warranted to evaluate the efficacy of AS [54]. The absence of preservatives and high nutrient level in ASE increases the risk of sample contamination $[55,56]$. Therefore, attention should be paid for the signs of infection in patients using ASE [36]. Lagnado et al. [55] recommended that sample vials should be stored frozen at $-20^{\circ} \mathrm{C}$ for up to 6 months, and each vial should be thawed and used for only 24 hours. A prospective randomized human study showed that containers equipped with a sterilizing filter can be used for up to 4 weeks without any increased risk of contamination [56]. The concentrations of growth factors in 20\% ASE remained stable for up to 9 months when kept frozen at $-20^{\circ} \mathrm{C}$ and up to 4 weeks when defrosted [57].

3.2. Allogeneic Serum Eye Drops (SE). Allogeneic SE from healthy donors can be advantageous in patients with fear or difficulty of blood sampling or coexisting blood disorders including anemia [58]. Moreover, it can also be a therapeutic option for patients with graft-versus-host disease (GVHD) or (SS), in which a considerable amount of proinflammatory cytokines could be included in their autologous serum [59]. Allogeneic SE can be prepared using the same protocol of ASE [58]. Because allogeneic SE includes anti-A and anti-B antibodies, it can theoretically cause an immune reaction against $\mathrm{ABO}$ antigens expressed on corneal and conjunctival epithelium [58]. Therefore, preparation of allogenic SE from $\mathrm{ABO}$-identical donors or blood type $\mathrm{AB}$ donors is recommended $[60,61]$. Studies demonstrated the efficacy of allogenic SE in DED, PED, neurotrophic keratitis, GVHD, and exposure keratopathy $[60,62,63]$, indicating its potential as a viable alternative to ASE [36].

3.3. Umbilical Cord Serum Eye Drops (UCSE). UCSE samples can be prepared using umbilical cord blood collected during delivery [36]. Rigorous screening for blood-borne infections is mandatory prior to donation $[36,58]$. UCSE can also be a therapeutic option for patients with blood disorders or systemic inflammatory diseases, in which ASE is contraindicated [58]. Although allogeneic serum does have the same advantage, UCS contains a higher level of growth factors, neurotrophic factors, and essential tear components compared to allogeneic serum [31, 33, 64]. Moreover, compared to allogeneic serum, a substantially larger amount of UCSE can be obtained with a single sampling from one donor and can be distributed to multiple patients [58]. As UCSE contains high levels of neurotrophic factors such as substance $\mathrm{P}$ (SP), insulin-like growth factor- (IGF-) 1 , and nerve growth 
factor (NGF) [32, 33], as well as growth factors including EGF and TGF- $\beta$ [64], it is conceivably helpful for corneal nerve regeneration and epithelial healing. Studies have revealed that UCSE accelerated the recovery of PED and neurotrophic keratitis recalcitrant to conventional treatment $[32,33]$. UCSE was shown to be more effective than ASE for the improvement of symptoms and signs of DED, particularly in severe cases associated with GVHD and SS [64, 65]. UCSE was superior to artificial tear in treating recurrent corneal erosions and reducing its recurrence [34]. In ocular chemical burn, UCSE resulted in faster corneal epithelial healing and milder corneal opacity compared to ASE or artificial tears [35]. UCSE is also shown to decrease early corneal haze and improve ocular surface parameters after laser epithelial keratomileusis (LASEK) [66].

3.4. Platelet-Derived Plasma Preparations. Platelet-derived plasma preparations contain a large amount of growth factors and cytokines $[36,58]$ and have been successfully used in maxillofacial and orthopedic surgery as well as in regenerative medicine for the promotion of tissue healing [67]. Various preparations have been developed, such as plasma rich in growth factors (PRGF), platelet-rich plasma (PRP), and platelet lysate [58]. PRGF is obtained by the filtration of plasma supernatants after centrifugation of the whole blood [68]. PRP is a plasma with increased concentrations of platelets obtained with an additional centrifugation of the whole blood [69]. Platelet lysate is collected by inducing platelet lysis and release of growth factors including platelet-derived growth factor (PDGF) using PRP [70].

Kim et al. [71] demonstrated that PRP was superior to ASE in the treatment of PED. PRGF was also suggested to be useful for the healing of PED [72]. PRP was shown to be effective for the improvement of both symptoms and signs of DED [73]. Plasma lysate was suggested to be helpful for the treatment of DED associated with GVHD or SS $[74,75]$. PRP was also superior to conventional treatment for the recovery of visual acuity and corneal transparency in patients with ocular chemical injury [76]. In addition, PRP is potentially available for a biomaterial for ocular surface reconstruction [77, 78].

\section{Growth Factors for Corneal Diseases}

4.1. Nerve Growth Factor (NGF). NGF facilitates corneal epithelial healing, which is mediated by the cleavage of $\beta 4$ integrin and the upregulation of matrix metalloproteinase-9 [79]. Topical administration of NGF was shown to be effective in neurotrophic keratitis refractory to conventional treatment [80-82]. NGF is also expected to be effective for the treatment of diabetic keratopathy, as it could alleviate inflammation and apoptosis of corneal cells that can occur in diabetes mellitus [83].

Topical NGF was also shown to have a beneficial effect for postoperative corneal wound healing [80]. Cellini et al. [84] demonstrated that topical NGF was superior to artificial tear for corneal reconstruction after cataract. Animal experimental studies revealed that topical application of NGF accelerated restoration of corneal sensitivity and promoted cornea epithelial proliferation and nerve regeneration after laser in situ keratomileusis (LASIK) or photorefractive keratectomy (PRK) [85-87].

\subsection{Substance P (SP) and Insulin-Like Growth Factor- (IGF-)} 1. A randomized prospective study revealed that topical SP and IGF-1 combination therapy was useful for the prevention of superficial punctate keratopathy after cataract surgery in diabetic patients [88]. SP was shown to promote an epithelial healing process in diabetic cornea and attenuate hyperosmotic stress-induced apoptosis of corneal epithelial cells through the neurokinin-1 receptor signaling pathway [89, 90]. IGF-1 also facilitated the regeneration of corneal surface ultrastructure and nerves after LASIK in rabbit eyes [91].

4.3. Vascular Endothelial Growth Factor (VEGF). VEGF can facilitate the functional and anatomical recovery after peripheral nerve damage [92]. Guaiquil et al. [93] demonstrated that VEGF-B treatment selectively promoted nerve regeneration and restored sensory and trophic functions of injured corneal nerves, suggesting that it might have a therapeutic potential for peripheral corneal nerve injury [93].

An experimental study revealed that the expression of endogenous VEGF-B was attenuated in regenerated corneal epithelium in a diabetic mouse model, whereas supplementation of exogenous VEGF-B accelerated corneal nerve regeneration [94].

4.4. Other Grow Factors. An animal study showed that pigment epithelial-derived factor, in conjunction with docosahexaenoic acid, might be effective for the treatment of DED caused by corneal nerve damage and neurotrophic keratitis [95]. Topical administration of neuroprotectin D1 was also shown to attenuate inflammation and facilitate nerve regeneration after corneal damage in a rabbit model [96]. Ciliary neurotrophic factor was shown to be able to activate corneal epithelial stem/progenitor cells and promote the corneal nerve regeneration and epithelial recovery, suggesting its therapeutic potential for diabetic keratopathy and limbal stem cell deficiency [97]. A randomized clinical study demonstrated that basic fibroblast growth factor promoted corneal epithelial healing after PRK, indicating it could be a therapeutic option for delayed healing [98].

4.5. Regenerating Agent Eye Drops (RGTAs). RGTA (OTR4120 Cacicol20 ${ }^{\circledR}$; Théa, Clermont-Ferrand, France) is a carboxymethyl dextran sulfate polymer bioengineered to replace heparan sulfate, which is an important factor both for matrix proteins and for growth factors $[99,100]$. Thus, RGTA is conceivably helpful for restoring equilibrium in cellular microenvironment $[99,101]$. It is also expected to be useful for corneal wound healing, and several studies have shown promising results [99-107].

Experimental studies using a rabbit corneal burn model and a clinical case series study suggested that RGTA might be an innovative agent for promoting corneal regeneration and attenuating ocular surface inflammation by reducing oxidative, proteolytic, and nitrosative corneal damage $[104,108,109]$. A clinical pilot study also revealed the efficacy of RGTA for corneal ulcers and dystrophies refractory 
TABLE 1: Effect and possible application of the novel drugs.

\begin{tabular}{|c|c|c|}
\hline Drug & Effect & Possible application \\
\hline \multirow[t]{2}{*}{ ROCK inhibitor } & Corneal endothelial cell regeneration & $\begin{array}{c}\text { Topical eye drops for recovery of corneal clarity in corneal } \\
\text { endothelial dysfunction }\end{array}$ \\
\hline & Promotion of corneal endothelial cell adhesion & Adjuvant therapy for the corneal endothelial cell injection \\
\hline \multirow{2}{*}{$\begin{array}{l}\text { Blood-derived } \\
\text { products }\end{array}$} & \multirow{2}{*}{$\begin{array}{l}\text { Promotion of healing of ocular surface } \\
\text { epithelium }\end{array}$} & Recovery of persistent epithelial defect or neurotrophic keratitis \\
\hline & & $\begin{array}{l}\text { Promoting ocular surface regeneration and prevention of corneal } \\
\text { haze after ocular chemical injury or keratorefractive surgery }\end{array}$ \\
\hline \multirow{3}{*}{ Growth factors } & \multirow{3}{*}{$\begin{array}{l}\text { Facilitation of corneal epithelial healing and } \\
\text { nerve regeneration }\end{array}$} & Treatment of persistent epithelial defect or neurotrophic keratitis \\
\hline & & Topical eye drops for diabetic keratopathy \\
\hline & & Recovery of cornea epithelium and nerve after keratorefractive surgery \\
\hline \multirow{3}{*}{ RGTA* } & \multirow{3}{*}{$\begin{array}{l}\text { Promotion of corneal regeneration and } \\
\text { attenuation of ocular surface inflammation }\end{array}$} & Treatment of persistent epithelial defect or neurotrophic keratitis \\
\hline & & Recovery of corneal epithelium after corneal cross-linking \\
\hline & & Corneal recovery after keratorefractive surgery \\
\hline
\end{tabular}

${ }^{*}$ RGTA: regenerating agent eye drops.

to conventional treatment [105]. A prospective clinical study demonstrated that RGTA might be effective and safe for the treatment of neurotrophic keratitis [106]. Chappelet et al. [101] recently showed that RGTA could be useful for the treatment of a PED after bacterial keratitis [101].

RGTA ophthalmic solution was also reported to facilitate corneal epithelial healing after corneal cross-linking (CXL) by reconstruction of the extracellular matrix in the corneal wound area $[99,100]$. A randomized clinical trial demonstrated that RGTA might be superior to topical hyaluronic acid for corneal wound recovery after CXL in patients with keratoconus [103].

In animal excimer laser models, topical RGTA reduced corneal haze and promoted nerve regeneration, suggesting that it could be a useful option for the restoration of corneal microarchitecture after keratorefractive surgery $[102,107]$.

\section{Conclusion}

In this review paper, we have introduced a number of research papers that have demonstrated the efficacy of pharmacologic therapies, such as ROCK inhibitors, blood-derived products, growth factors, and RGTA on corneal cell regeneration. The promising results of these studies suggest that these agents can be viable options to aid corneal cell regeneration.

In summary, the ROCK inhibitor can promote the regeneration of CECs and its adhesion to Descemet's membrane. Thus, it can be used as a topical eye drops for the treatment of corneal endothelial dysfunction. It can also be used as an adjuvant therapy for CEC injection to AC. Blood-derived products can promote healing of ocular surface epithelium. Hence, it can be used for PED or neurotrophic keratitis. It can also be used for promoting ocular surface reconstruction and prevention of corneal opacity after ocular chemical injury. Growth factors promote the recovery of cornea epithelium and nerve; thus, these drugs can especially be helpful for PED, neurotrophic keratitis, and diabetic keratopathy. As RGTA facilitates corneal regeneration and attenuates ocular surface inflammation, it can be indicated for corneal regeneration after corneal CXL. It can also be helpful for the treatment of PDE or neurotrophic keratitis. The recovery of corneal epithelium and nerve after keratorefractive surgery can be facilitated by blood-derived products, growth factors, and RGTA (Table 1).

Although these therapeutic agents are innovative, further prospective randomized studies are needed for the verification of the efficacy and safety of the drugs [3]. Further studies are also required for the development of novel therapeutic agents for corneal cell regeneration.

\section{Conflicts of Interest}

None of the authors have a proprietary interest in the study or financial interests to disclose.

\section{Acknowledgments}

This study was supported by 2017 Research Grant from Kangwon National University.

\section{References}

[1] J. P. Whitcher, M. Srinivasan, and M. P. Upadhyay, "Corneal blindness: a global perspective," Bulletin of the World Health Organization, vol. 79, no. 3, pp. 214-221, 2001.

[2] N. Okumura, Y. Sakamoto, K. Fujii et al., "Rho kinase inhibitor enables cell-based therapy for corneal endothelial dysfunction," Scientific Reports, vol. 6, no. 1, article 26113, 2016.

[3] N. Okumura, S. Kinoshita, and N. Koizumi, "Application of Rho kinase inhibitors for the treatment of corneal endothelial diseases," Journal of Ophthalmology, vol. 2017, Article ID 2646904, 8 pages, 2017.

[4] R. Nourinia, S. Nakao, S. Zandi, S. Safi, A. Hafezi-Moghadam, and H. Ahmadieh, "ROCK inhibitors for the treatment of ocular diseases," British Journal of Ophthalmology, vol. 102, no. 1, 2017.

[5] N. Koizumi, N. Okumura, M. Ueno, and S. Kinoshita, "New therapeutic modality for corneal endothelial disease using Rho-associated kinase inhibitor eye drops," Cornea, vol. 33, Supplement 11, pp. S25-S31, 2014. 
[6] N. Okumura, N. Koizumi, M. Ueno et al., "Enhancement of corneal endothelium wound healing by Rho-associated kinase (ROCK) inhibitor eye drops," British Journal of Ophthalmology, vol. 95, no. 7, pp. 1006-1009, 2011.

[7] N. Okumura, S. Nakano, E. D. P. Kay et al., "Involvement of cyclin D and p27 in cell proliferation mediated by ROCK inhibitors Y-27632 and Y-39983 during corneal endothelium wound healing," Investigative Ophthalmology \& Visual Science, vol. 55, no. 1, pp. 318-329, 2014.

[8] G. S. L. Peh, K. Adnan, B. L. George et al., "The effects of Rho-associated kinase inhibitor Y-27632 on primary human corneal endothelial cells propagated using a dual media approach," Scientific Reports, vol. 5, no. 1, p. 9167, 2015.

[9] A. Pipparelli, Y. Arsenijevic, G. Thuret, P. Gain, M. Nicolas, and F. Majo, "ROCK inhibitor enhances adhesion and wound healing of human corneal endothelial cells," PLoS One, vol. 8, no. 4, article e62095, 2013.

[10] N. Okumura, N. Koizumi, M. Ueno et al., "The new therapeutic concept of using a rho kinase inhibitor for the treatment of corneal endothelial dysfunction," Cornea, vol. 30, Supplement 1, pp. S54-S59, 2011.

[11] N. Okumura, N. Koizumi, E. D. P. Kay et al., "The ROCK inhibitor eye drop accelerates corneal endothelium wound healing," Investigative Ophthalmology \& Visual Science, vol. 54, no. 4, pp. 2493-2502, 2013.

[12] N. Okumura, M. Ueno, N. Koizumi et al., "Enhancement on primate corneal endothelial cell survival in vitro by a ROCK inhibitor," Investigative Ophthalmology \& Visual Science, vol. 50, no. 8, pp. 3680-3687, 2009.

[13] N. Okumura, S. Kinoshita, and N. Koizumi, "The role of rho kinase inhibitors in corneal endothelial dysfunction," Current Pharmaceutical Design, vol. 23, no. 4, pp. 660-666, 2017.

[14] N. Koizumi, N. Okumura, M. Ueno, H. Nakagawa, J. Hamuro, and S. Kinoshita, "Rho-associated kinase inhibitor eye drop treatment as a possible medical treatment for Fuchs corneal dystrophy," Cornea, vol. 32, no. 8, pp. 11671170,2013

[15] G. Moloney, C. Petsoglou, M. Ball et al., "Descemetorhexis without grafting for Fuchs endothelial dystrophysupplementation with topical ripasudil," Cornea, vol. 36, no. 6, pp. 642-648, 2017.

[16] N. Koizumi, Y. Sakamoto, N. Okumura et al., "Cultivated corneal endothelial cell sheet transplantation in a primate model," Investigative Ophthalmology \& Visual Science, vol. 48, no. 10, pp. 4519-4526, 2007.

[17] T. Mimura, S. Yamagami, S. Yokoo et al., "Cultured human corneal endothelial cell transplantation with a collagen sheet in a rabbit model," Investigative Ophthalmology \& Visual Science, vol. 45, no. 9, pp. 2992-2997, 2004.

[18] T. Mimura, N. Shimomura, T. Usui et al., "Magnetic attraction of iron-endocytosed corneal endothelial cells to Descemet's membrane," Experimental Eye Research, vol. 76, no. 6, pp. 745-751, 2003.

[19] T. Mimura, S. Yamagami, T. Usui et al., "Long-term outcome of iron-endocytosing cultured corneal endothelial cell transplantation with magnetic attraction," Experimental Eye Research, vol. 80, no. 2, pp. 149-157, 2005.

[20] I. H. Ma, L. W. Chen, W. H. Tu, C. J. Lu, C. J. Huang, and W. L. Chen, "Serum components and clinical efficacies of autologous serum eye drops in dry eye patients with active and inactive Sjogren syndrome," Taiwan Journal of Ophthalmology, vol. 7, no. 4, pp. 213-220, 2017.

[21] T. Mimura, S. Yamagami, S. Yokoo et al., "Sphere therapy for corneal endothelium deficiency in a rabbit model," Investigative Ophthalmology \& Visual Science, vol. 46, no. 9, pp. 3128 3135, 2005.

[22] N. Okumura, N. Koizumi, M. Ueno et al., "ROCK inhibitor converts corneal endothelial cells into a phenotype capable of regenerating in vivo endothelial tissue," The American Journal of Pathology, vol. 181, no. 1, pp. 268277, 2012.

[23] C. C. Sun, H. T. Chiu, Y. F. Lin, K. Y. Lee, and J. H. S. Pang, "Y-27632, a ROCK inhibitor, promoted limbal epithelial cell proliferation and corneal wound healing," PLoS One, vol. 10, no. 12, article e0144571, 2015.

[24] Q. Zhou, H. Duan, Y. Wang, M. Qu, L. Yang, and L. Xie, "ROCK inhibitor Y-27632 increases the cloning efficiency of limbal stem/progenitor cells by improving their adherence and ROS-scavenging capacity," Tissue Engineering. Part C: Methods, vol. 19, no. 7, pp. 531-537, 2013.

[25] M. Yamamoto, A. J. Quantock, R. D. Young et al., “A selective inhibitor of the Rho kinase pathway, Y-27632, and its influence on wound healing in the corneal stroma," Molecular Vision, vol. 18, pp. 1727-1739, 2012.

[26] P. Zeng, R. B. Pi, P. Li et al., "Fasudil hydrochloride, a potent ROCK inhibitor, inhibits corneal neovascularization after alkali burns in mice," Molecular Vision, vol. 21, pp. 688698, 2015.

[27] D. Sijnave, T. Van Bergen, K. Castermans et al., "Inhibition of Rho-associated kinase prevents pathological wound healing and neovascularization after corneal trauma," Cornea, vol. 34, no. 9, pp. 1120-1129, 2015.

[28] R. A. Ralph, M. G. Doane, and C. H. Dohlman, "Clinical experience with a mobile ocular perfusion pump," Archives of Ophthalmology, vol. 93, no. 10, pp. 1039-1043, 1975.

[29] K. Tsubota, E. Goto, S. Shimmura, and J. Shimazaki, "Treatment of persistent corneal epithelial defect by autologous serum application," Ophthalmology, vol. 106, no. 10, pp. 1984-1989, 1999.

[30] K. Tsubota, E. Goto, H. Fujita et al., "Treatment of dry eye by autologous serum application in Sjogren's syndrome," British Journal of Ophthalmology, vol. 83, no. 4, pp. 390-395, 1999.

[31] K. C. Yoon, S. K. Im, Y. G. Park, Y. D. Jung, S. Y. Yang, and J. Choi, "Application of umbilical cord serum eyedrops for the treatment of dry eye syndrome," Cornea, vol. 25, no. 3, pp. 268-272, 2006.

[32] K. C. Yoon, H. Heo, I. Y. Jeong, and Y. G. Park, "Therapeutic effect of umbilical cord serum eyedrops for persistent corneal epithelial defect," Korean Journal of Ophthalmology, vol. 19, no. 3, pp. 174-178, 2005.

[33] K. C. Yoon, I. C. You, S. K. Im, T. S. Jeong, Y. G. Park, and J. Choi, "Application of umbilical cord serum eyedrops for the treatment of neurotrophic keratitis," Ophthalmology, vol. 114, no. 9, pp. 1637-1642.e2, 2007.

[34] K. C. Yoon, W. Choi, I. C. You, and J. Choi, “Application of umbilical cord serum eyedrops for recurrent corneal erosions," Cornea, vol. 30, no. 7, pp. 744-748, 2011.

[35] N. Sharma, M. Goel, T. Velpandian, J. S. Titiyal, R. Tandon, and R. B. Vajpayee, "Evaluation of umbilical cord serum therapy in acute ocular chemical burns," Investigative Ophthalmology \& Visual Science, vol. 52, no. 2, pp. 1087-1092, 2011. 
[36] N. G. Soni and B. H. Jeng, "Blood-derived topical therapy for ocular surface diseases," British Journal of Ophthalmology, vol. 100, no. 1, pp. 22-27, 2015.

[37] G. Geerling, S. Maclennan, and D. Hartwig, "Autologous serum eye drops for ocular surface disorders," British Journal of Ophthalmology, vol. 88, no. 11, pp. 1467-1474, 2004.

[38] C. Yamada, K. E. King, and P. M. Ness, "Autologous serum eyedrops: literature review and implications for transfusion medicine specialists," Transfusion, vol. 48, no. 6, pp. 1245$1255,2008$.

[39] L. Liu, D. Hartwig, S. Harloff, P. Herminghaus, T. Wedel, and G. Geerling, "An optimised protocol for the production of autologous serum eyedrops," Graefe's Archive for Clinical and Experimental Ophthalmology, vol. 243, no. 7, pp. 706$714,2005$.

[40] B. H. Jeng and W. J. Dupps Jr, “Autologous serum 50\% eyedrops in the treatment of persistent corneal epithelial defects," Cornea, vol. 28, no. 10, pp. 1104-1108, 2009.

[41] K. Lekhanont, P. Jongkhajornpong, L. Choubtum, and V. Chuckpaiwong, "Topical 100\% serum eye drops for treating corneal epithelial defect after ocular surgery," BioMed Research International, vol. 2013, Article ID 521315, 7 pages, 2013.

[42] Y. K. Cho, W. Huang, G. Y. Kim, and B. S. Lim, "Comparison of autologous serum eye drops with different diluents," Current Eye Research, vol. 38, no. 1, pp. 9-17, 2013.

[43] B. A. Noble, R. S. Loh, S. MacLennan et al., "Comparison of autologous serum eye drops with conventional therapy in a randomised controlled crossover trial for ocular surface disease," British Journal of Ophthalmology, vol. 88, no. 5, pp. 647-652, 2004.

[44] T. Kojima, R. Ishida, M. Dogru et al., "The effect of autologous serum eyedrops in the treatment of severe dry eye disease: a prospective randomized case-control study," American Journal of Ophthalmology, vol. 139, no. 2, pp. 242-246, 2005.

[45] A. R. C. Celebi, C. Ulusoy, and G. E. Mirza, "The efficacy of autologous serum eye drops for severe dry eye syndrome: a randomized double-blind crossover study," Graefe's Archive for Clinical and Experimental Ophthalmology, vol. 252, no. 4, pp. 619-626, 2014.

[46] T. Kojima, A. Higuchi, E. Goto, Y. Matsumoto, M. Dogru, and K. Tsubota, "Autologous serum eye drops for the treatment of dry eye diseases," Cornea, vol. 27, Supplement 1, pp. S25-S30, 2008.

[47] T. Noda-Tsuruya, N. Asano-Kato, I. Toda, and K. Tsubota, "Autologous serum eye drops for dry eye after LASIK," Journal of Refractive Surgery, vol. 22, no. 1, pp. 61-66, 2006.

[48] A. C. Poon, G. Geerling, J. K. Dart, G. E. Fraenkel, and J. T. Daniels, "Autologous serum eyedrops for dry eyes and epithelial defects: clinical and in vitro toxicity studies," British Journal of Ophthalmology, vol. 85, no. 10, pp. 1188-1197, 2001.

[49] S. Schrader, T. Wedel, R. Moll, and G. Geerling, "Combination of serum eye drops with hydrogel bandage contact lenses in the treatment of persistent epithelial defects," Graefe's Archive for Clinical and Experimental Ophthalmology, vol. 244, no. 10, pp. 1345-1349, 2006.

[50] Y. M. Chen, F. R. Hu, J. Y. Huang, E. P. Shen, T. Y. Tsai, and W. L. Chen, "The effect of topical autologous serum on graft re-epithelialization after penetrating keratoplasty," American
Journal of Ophthalmology, vol. 150, no. 3, pp. 352-359.e2, 2010.

[51] Y. Matsumoto, M. Dogru, E. Goto et al., "Autologous serum application in the treatment of neurotrophic keratopathy," Ophthalmology, vol. 111, no. 6, pp. 1115-1120, 2004.

[52] J. S. Lopez-Garcia, L. Rivas, I. Garcia-Lozano, and J. Murube, "Autologous serum eyedrops in the treatment of aniridic keratopathy," Ophthalmology, vol. 115, no. 2, pp. 262-267, 2008.

[53] N. G. Ziakas, K. G. Boboridis, C. Terzidou et al., "Long-term follow up of autologous serum treatment for recurrent corneal erosions," Clinical \& Experimental Ophthalmology, vol. 38, no. 7, pp. 683-687, 2010.

[54] Q. Pan, A. Angelina, M. Marrone et al., "Autologous serum eye drops for dry eye," Cochrane Database of Systematic Reviews, vol. 2, article CD009327, 2017.

[55] R. Lagnado, A. J. King, F. Donald, and H. S. Dua, “A protocol for low contamination risk of autologous serum drops in the management of ocular surface disorders," British Journal of Ophthalmology, vol. 88, no. 4, pp. 464-465, 2004.

[56] J. S. Lopez-Garcia and I. Garcia-Lozano, "Use of containers with sterilizing filter in autologous serum eyedrops," Ophthalmology, vol. 119, no. 11, pp. 2225-2230, 2012.

[57] J. S. Lopez-Garcia, I. Garcia-Lozano, L. Rivas, N. Ramírez, M. T. Méndez, and R. Raposo, "Stability of growth factors in autologous serum eyedrops after long-term storage," Current Eye Research, vol. 41, no. 3, pp. 1-7, 2016.

[58] G. Giannaccare, P. Versura, M. Buzzi, L. Primavera, M. Pellegrini, and E. C. Campos, "Blood derived eye drops for the treatment of cornea and ocular surface diseases," Transfusion and Apheresis Science, vol. 56, no. 4, pp. 595604, 2017.

[59] P. A. Stenwall, M. Bergstrom, P. Seiron et al., "Improving the anti-inflammatory effect of serum eye drops using allogeneic serum permissive for regulatory $\mathrm{T}$ cell induction," Acta Ophthalmologica, vol. 93, no. 7, pp. 654-657, 2015.

[60] L. H. Harritshoj, C. Nielsen, H. Ullum, M. B. Hansen, and H. O. Julian, "Ready-made allogeneic ABO-specific serum eye drops: production from regular male blood donors, clinical routine, safety and efficacy," Acta Ophthalmologica, vol. 92, no. 8, pp. 783-786, 2014.

[61] K. G. Badami and M. McKellar, "Allogeneic serum eye drops: time these became the norm?," British Journal of Ophthalmology, vol. 96, no. 8, pp. 1151-1152, 2012.

[62] C. C. Chiang, W. L. Chen, J. M. Lin, and Y. Y. Tsai, "Allogeneic serum eye drops for the treatment of persistent corneal epithelial defect,” Eye, vol. 23, no. 2, pp. 290-293, 2009.

[63] K. S. Na and M. S. Kim, "Allogeneic serum eye drops for the treatment of dry eye patients with chronic graft-versus-host disease," Journal of Ocular Pharmacology and Therapeutics, vol. 28, no. 5, pp. 479-483, 2012.

[64] K. C. Yoon, H. Heo, S. K. Im, I. C. You, Y. H. Kim, and Y. G. Park, "Comparison of autologous serum and umbilical cord serum eye drops for dry eye syndrome," American Journal of Ophthalmology, vol. 144, no. 1, pp. 86-92.e2, 2007.

[65] K. C. Yoon, I. Y. Jeong, S. K. Im, Y. G. Park, H. J. Kim, and J. Choi, "Therapeutic effect of umbilical cord serum eyedrops for the treatment of dry eye associated with graft-versus-host disease," Bone Marrow Transplantation, vol. 39, no. 4, pp. 231-235, 2007.

[66] K. C. Yoon, H. J. Oh, J. W. Park, and J. Choi, "Application of umbilical cord serum eyedrops after laser epithelial 
keratomileusis," Acta Ophthalmologica, vol. 91, no. 1, pp. e22-e28, 2013.

[67] B. H. Choi, C. J. Im, J. Y. Huh, J. J. Suh, and S. H. Lee, "Effect of platelet-rich plasma on bone regeneration in autogenous bone graft," International Journal of Oral and Maxillofacial Surgery, vol. 33, no. 1, pp. 56-59, 2004.

[68] E. Anitua, M. de la Fuente, F. Muruzabal, A. Riestra, J. MerayoLloves, and G. Orive, "Plasma rich in growth factors (PRGF) eye drops stimulates scarless regeneration compared to autologous serum in the ocular surface stromal fibroblasts," Experimental Eye Research, vol. 135, pp. 118-126, 2015.

[69] S. T. Tanidir, N. Yuksel, O. Altintas, D. K. Yildiz, E. Sener, and Y. Caglar, "The effect of subconjunctival platelet-rich plasma on corneal epithelial wound healing," Cornea, vol. 29, no. 6, pp. 664-669, 2010.

[70] L. Liu, D. Hartwig, S. Harloff et al., "Corneal epitheliotrophic capacity of three different blood-derived preparations," Investigative Ophthalmology \& Visual Science, vol. 47, no. 6, pp. 2438-2444, 2006.

[71] K. M. Kim, Y. T. Shin, and H. K. Kim, "Effect of autologous platelet-rich plasma on persistent corneal epithelial defect after infectious keratitis," Japanese Journal of Ophthalmology, vol. 56, no. 6, pp. 544-550, 2012.

[72] S. Lopez-Plandolit, M. C. Morales, V. Freire, J. Etxebarría, and J. A. Durán, "Plasma rich in growth factors as a therapeutic agent for persistent corneal epithelial defects," Cornea, vol. 29, no. 8, pp. 843-848, 2010.

[73] J. L. Alio, A. E. Rodriguez, R. Ferreira-Oliveira, D. WróbelDudzińska, and A. A. Abdelghany, "Treatment of dry eye disease with autologous platelet-rich plasma: a prospective, interventional, non-randomized study," Ophthalmology and Therapy, vol. 6, no. 2, pp. 285-293, 2017.

[74] S. Pezzotta, C. Del Fante, L. Scudeller, M. Cervio, E. R. Antoniazzi, and C. Perotti, "Autologous platelet lysate for treatment of refractory ocular GVHD," Bone Marrow Transplantation, vol. 47, no. 12, pp. 1558-1563, 2012.

[75] A. M. Fea, V. Aragno, V. Testa et al., "The effect of autologous platelet lysate eye drops: an in vivo confocal microscopy study," BioMed Research International, vol. 2016, Article ID 8406832, 10 pages, 2016.

[76] A. Panda, M. Jain, M. Vanathi, T. Velpandian, S. Khokhar, and T. Dada, "Topical autologous platelet-rich plasma eyedrops for acute corneal chemical injury," Cornea, vol. 31, no. 9, pp. 989-993, 2012.

[77] J. L. Alio, A. E. Rodriguez, and L. M. Martinez, "Bovine pericardium membrane (tutopatch) combined with solid platelet-rich plasma for the management of perforated corneal ulcers," Cornea, vol. 32, no. 5, pp. 619-624, 2013.

[78] J. L. Alio, A. E. Rodriguez, L. M. Martinez, and A. L. Rio, "Autologous fibrin membrane combined with solid plateletrich plasma in the management of perforated corneal ulcers: a pilot study," JAMA Ophthalmology, vol. 131, no. 6, pp. 745$751,2013$.

[79] T. Blanco-Mezquita, C. Martinez-Garcia, R. Proenca et al., "Nerve growth factor promotes corneal epithelial migration by enhancing expression of matrix metalloprotease-9," Investigative Ophthalmology \& Visual Science, vol. 54, no. 6, pp. 3880-3890, 2013.

[80] A. Lambiase, M. Sacchetti, and S. Bonini, "Nerve growth factor therapy for corneal disease," Current Opinion in Ophthalmology, vol. 23, no. 4, pp. 296-302, 2012.
[81] F. R. Ghosheh, F. Cremona, B. D. Ayres et al., "Indications for penetrating keratoplasty and associated procedures, 20012005," Eye \& Contact Lens, vol. 34, no. 4, pp. 211-214, 2008.

[82] S. Bonini, A. Lambiase, P. Rama, G. Caprioglio, and L. Aloe, "Topical treatment with nerve growth factor for neurotrophic keratitis," Ophthalmology, vol. 107, no. 7, pp. 1347-1351, 2000.

[83] J. H. Park, S. S. Kang, J. Y. Kim, and H. Tchah, "Nerve growth factor attenuates apoptosis and inflammation in the diabetic cornea," Investigative Ophthalmology \& Visual Science, vol. 57, no. 15, pp. 6767-6775, 2016.

[84] M. Cellini, E. Bendo, G. O. Bravetti, and E. C. Campos, "The use of nerve growth factor in surgical wound healing of the cornea," Ophthalmic Research, vol. 38, no. 4, pp. 177-181, 2006.

[85] M. J. Joo, K. R. Yuhan, J. Y. Hyon et al., "The effect of nerve growth factor on corneal sensitivity after laser in situ keratomileusis," Archives of Ophthalmology, vol. 122, no. 9, pp. 1338-1341, 2004.

[86] S. Esquenazi, H. E. P. Bazan, V. Bui, J. He, D. B. Kim, and N. G. Bazan, "Topical combination of NGF and DHA increases rabbit corneal nerve regeneration after photorefractive keratectomy," Investigative Ophthalmology \& Visual Science, vol. 46, no. 9, pp. 3121-3127, 2005.

[87] K. Ma, N. Yan, Y. Huang, G. Cao, J. Deng, and Y. Deng, "Effects of nerve growth factor on nerve regeneration after corneal nerve damage," International Journal of Clinical and Experimental Medicine, vol. 7, no. 11, pp. 4584-4589, 2014.

[88] N. Chikamoto, T. Chikama, N. Yamada, T. Nishida, T. Ishimitsu, and A. Kamiya, "Efficacy of substance P and insulin-like growth factor-1 peptides for preventing postsurgical superficial punctate keratopathy in diabetic patients," Japanese Journal of Ophthalmology, vol. 53, no. 5, pp. 464469, 2009.

[89] L. Yang, G. Di, X. Qi et al., "Substance P promotes diabetic corneal epithelial wound healing through molecular mechanisms mediated via the neurokinin-1 receptor," Diabetes, vol. 63, no. 12, pp. 4262-4274, 2014.

[90] L. Yang, W. Sui, Y. Li et al., "Substance P inhibits hyperosmotic stress-induced apoptosis in corneal epithelial cells through the mechanism of Akt activation and reactive oxygen species scavenging via the neurokinin-1 receptor," PLoS One, vol. 11, no. 2, article e0149865, 2016.

[91] C. Wang, Y. Peng, S. Pan, and L. Li, "Effect of insulin-like growth factor-1 on corneal surface ultrastructure and nerve regeneration of rabbit eyes after laser in situ keratomileusis," Neuroscience Letters, vol. 558, pp. 169-174, 2014.

[92] Z. Pan, S. Fukuoka, N. Karagianni, V. H. Guaiquil, and M. I. Rosenblatt, "Vascular endothelial growth factor promotes anatomical and functional recovery of injured peripheral nerves in the avascular cornea," The FASEB Journal, vol. 27, no. 7, pp. 2756-2767, 2013.

[93] V. H. Guaiquil, Z. Pan, N. Karagianni, S. Fukuoka, G. Alegre, and M. I. Rosenblatt, "VEGF-B selectively regenerates injured peripheral neurons and restores sensory and trophic functions," Proceedings of the National Academy of Sciences of the United States of America, vol. 111, no. 48, pp. 1727217277, 2014.

[94] G. Di, X. Zhao, X. Qi et al., "VEGF-B promotes recovery of corneal innervations and trophic functions in diabetic mice," Scientific Reports, vol. 7, article 40582, 2017. 
[95] J. He, M. S. Cortina, A. Kakazu, and H. E. P. Bazan, "The PEDF neuroprotective domain plus DHA induces corneal nerve regeneration after experimental surgery," Investigative Ophthalmology \& Visual Science, vol. 56, no. 6, pp. 3505$3513,2015$.

[96] M. S. Cortina, J. He, T. Russ, N. G. Bazan, and H. E. P. Bazan, "Neuroprotectin D1 restores corneal nerve integrity and function after damage from experimental surgery," Investigative Ophthalmology \& Visual Science, vol. 54, no. 6, pp. 41094116, 2013.

[97] Q. Zhou, P. Chen, G. Di et al., "Ciliary neurotrophic factor promotes the activation of corneal epithelial stem/progenitor cells and accelerates corneal epithelial wound healing," Stem Cells, vol. 33, no. 5, pp. 1566-1576, 2015.

[98] A. Meduri, P. Aragona, P. L. Grenga, and A. M. Roszkowska, "Effect of basic fibroblast growth factor on corneal epithelial healing after photorefractive keratectomy," Journal of Refractive Surgery, vol. 28, no. 3, pp. 220-223, 2012.

[99] K. Gumus, M. G. Guerra, S. H. de Melo Marques, S. Karaküçük, and D. Barritault, "A new matrix therapy agent for faster corneal healing and less ocular discomfort following epi-off accelerated corneal cross-linking in progressive keratoconus," Journal of Refractive Surgery, vol. 33, no. 3, pp. 163-170, 2017.

[100] G. D. Kymionis, D. A. Liakopoulos, M. A. Grentzelos et al., "Effect of the regenerative agent poly(carboxymethylglucose sulfate) on corneal wound healing after corneal crosslinking for keratoconus," Cornea, vol. 34, no. 8, pp. 928931, 2015.

[101] M. A. Chappelet, D. Bernheim, C. Chiquet, and F. Aptel, "Effect of a new matrix therapy agent in persistent epithelial defects after bacterial keratitis treated with topical fortified antibiotics," Cornea, vol. 36, no. 9, pp. 1061-1068, 2017.

[102] I. Alcalde, A. Inigo-Portugues, N. Carreño, A. C. Riestra, and J. M. Merayo-Lloves, "Effects of new biomimetic regenerating agents on corneal wound healing in an experimental model of post-surgical corneal ulcers," Archivos de la Sociedad Española de Oftalmología, vol. 90, no. 10, pp. 467-474, 2015.

[103] A. M. Bata, K. J. Witkowska, P. A. Wozniak et al., "Effect of a matrix therapy agent on corneal epithelial healing after standard collagen cross-linking in patients with keratoconus: a randomized clinical trial," JAMA Ophthalmology, vol. 134, no. 10, pp. 1169-1176, 2016.

[104] F. Brignole-Baudouin, J. M. Warnet, D. Barritault, and C. Baudouin, "RGTA-based matrix therapy in severe experimental corneal lesions: safety and efficacy studies," Journal Français d'Ophtalmologie, vol. 36, no. 9, pp. 740-747, 2013.

[105] C. K. Chebbi, K. Kichenin, N. Amar et al., "Pilot study of a new matrix therapy agent (RGTA OTR4120) in treatmentresistant corneal ulcers and corneal dystrophy," Journal Français d'Ophtalmologie, vol. 31, no. 5, pp. 465-471, 2008.

[106] M. Guerra, S. Marques, J. Q. Gil et al., "Neurotrophic keratopathy: therapeutic approach using a novel matrix regenerating agent," Journal of Ocular Pharmacology and Therapeutics, vol. 33, no. 9, pp. 662-669, 2017.

[107] M. Xeroudaki, B. Peebo, J. Germundsson, P. Fagerholm, and N. Lagali, "RGTA in corneal wound healing after transepithelial laser ablation in a rabbit model: a randomized, blinded, placebo-controlled study," Acta Ophthalmologica, vol. 94, no. 7, pp. 685-691, 2016.
[108] R. P. J. Arvola, A. Robciuc, and J. M. Holopainen, "Matrix regeneration therapy: a case series of corneal neurotrophic ulcers," Cornea, vol. 35, no. 4, pp. 451-455, 2016.

[109] J. Cejkova, C. Olmiere, C. Cejka, P. Trosan, and V. Holan, "The healing of alkali-injured cornea is stimulated by a novel matrix regenerating agent (RGTA, CACICOL20): a biopolymer mimicking heparan sulfates reducing proteolytic, oxidative and nitrosative damage," Histology and Histopathology, vol. 29, no. 4, pp. 457-478, 2014. 


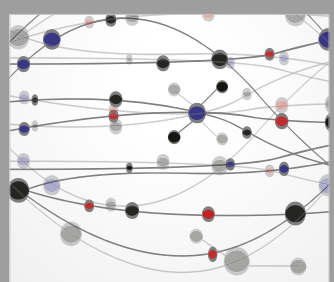

The Scientific World Journal
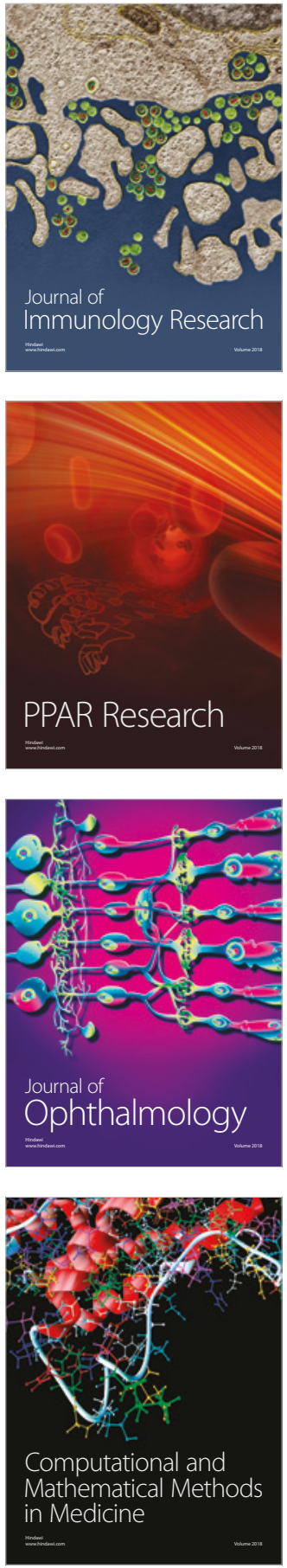

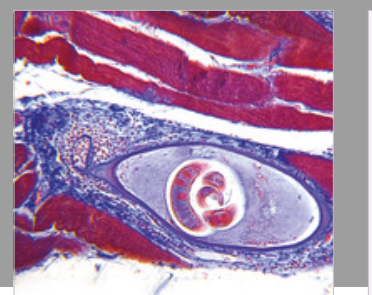

Gastroenterology Research and Practice

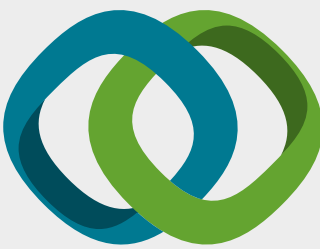

\section{Hindawi}

Submit your manuscripts at

www.hindawi.com
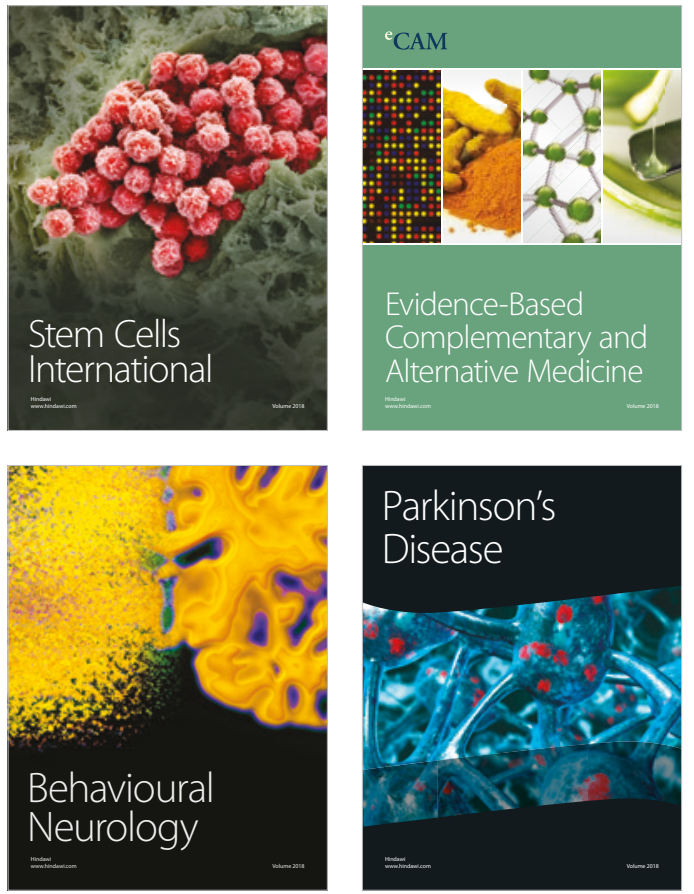

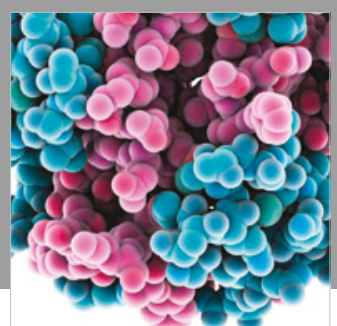

ournal of

Diabetes Research

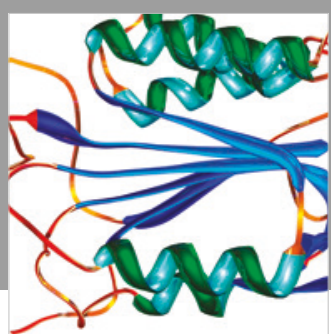

Disease Markers
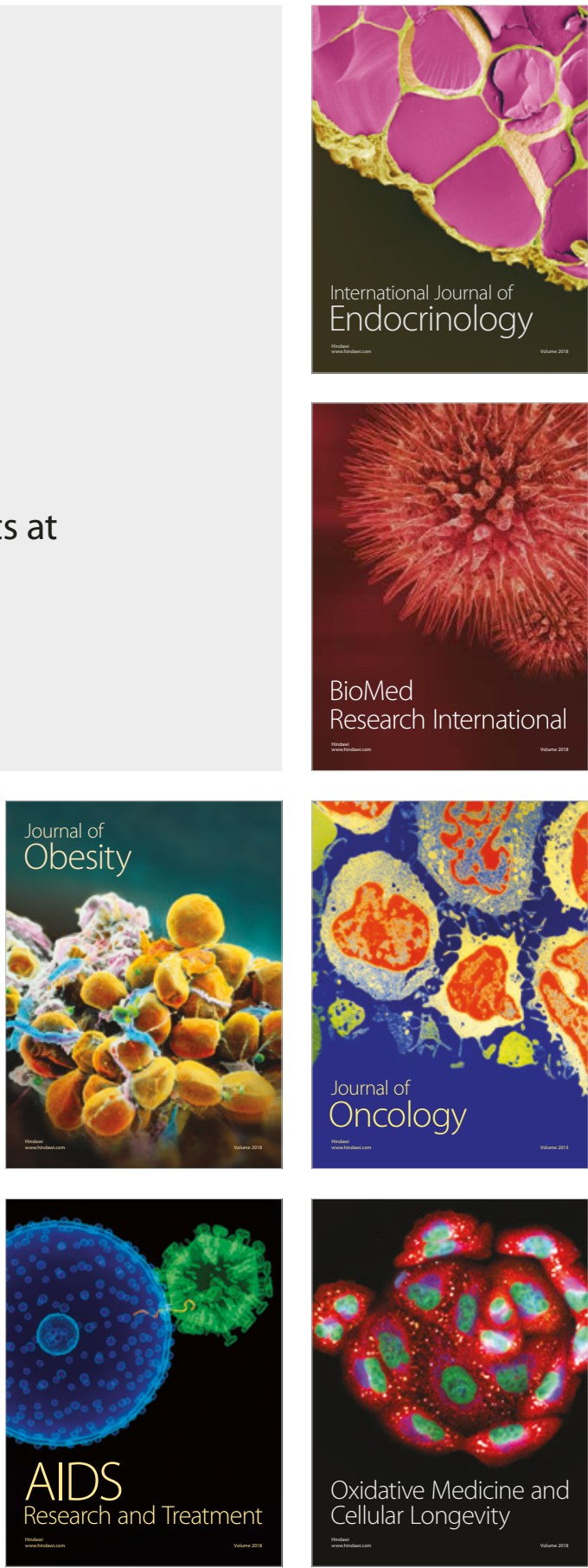